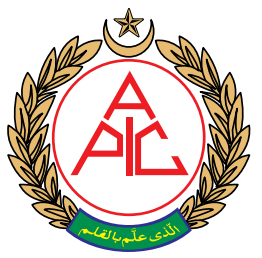

${ }^{1}$ Associate Professor, Director Research and Development, Nowshera Medical College, Nowshera, Pakistan

${ }^{2}$ Assistant Professor Pediatrics, Nowshera Medical College, Nowshera, Pakistan.

${ }^{3}$ Professor \& Head Department of Hematology Hayatabad Medical Complex, Chairperson Provincial Passive Immunization Committee for use of plasma from convalescent COVID-19 positive patients. Peshawar, Pakistan.

${ }^{4}$ Focal person COVID-19, District Health Office, Nowshera. Pakistan.

Correspondence:

Hamzullah Khan,

Associate Professor, Director Research and Development, Nowshera Medical College, Nowshera, Pakistan.

E-mail:

hamzakmc@gmail.com;

Phone: +92 3344802902

Received: 20 April 2020, Reviewed: 25 April 2020, Accepted: 30 April 2020

\section{Risk factors and symptoms stratification and mortality of COVID-19 in population of Nowshera (Pakistan)}

\author{
Hamzullah Khan ${ }^{1}$, Khalid Khan ${ }^{2}$, Shahtaj Khan ${ }^{3}$, Abu Zar ${ }^{4}$
}

\section{ABSTRACT}

Background \& Objectives: COVID-19 has spread around the globe, and our country is no exception. We have been actively observing and managing these patients and have recorded the salient features including risk factors, the presenting complaints and also the trends of mortality.

We aimed to have risk factors stratification, prevalent symptoms at the time of presentation to the hospital and to determine factors contributing to mortality due to COVID-19 in population of Nowshera (Pakistan).

Methodology: In this cross sectional study, 75 cases with returned PCR results were included from 15th February 2020 to 18th April 2020. Data were entered in a format in SPSS version 25, prepared in accordance with the objectives of the study.

Results: Out of a total of 75 patients, $20(26.67 \%)$ were females and $55(73.33 \%)$ were males. The mean age was $36 \pm 18 \mathrm{y}$. Out of these, $29(38.67 \%)$ patients were COVID-19 positive by PCR technique, and $46(61.33 \%)$ were negative. The probability of virus detection was higher in male gender $(\mathrm{OR}=1.5$, Relative Risk $(R R)=1.2)$. A significant relation of viral infectivity was noted with history of travel to an epidemic area $(p=0.01 \mathrm{OR}=3.85, \mathrm{RR}=1.5)$ and history of contacts with COVID-19 infected person/s $(p=0.018$, $O R=3.5, R R=2.3)$. A high mortality rate of $3 / 29(10.34 \%)$ for positive COVID-19 cases was recorded. The probability of worse outcome in term of death in COVID-19 positive patients was $(p=0.5, O R=$ 2.1). Regarding symptoms selection; contact and travel history without any symptoms has a reliability index (RI) of $12 / 35$ (34\%) for infectivity. Cough, fever with shortness of breath (RI; $8 / 12(67 \%)$ for positive cases followed by fever and cough with $\mathrm{RI}$ of $6 / 10(60 \%)$ cases etc. Sore throat $(\mathrm{RI} ; 1 / 13(8 \%)$ and flue only $(\mathrm{Rl} ; 0 / 3(0 \%)$ proved non-reliable symptoms. When plotted the survival graphs of COVID positive vs. COVID negative cases, a similar pattern was recorded that showed the mortality rate in the positive cases was not solely due to COVID-19, though being opportunistic infection, it would have contributed. We recorded refractory COVID-19 in 4/29 (13.79\%) cases.

Conclusion: We conclude that male gender with history of travel to an epidemic area and contact with COVID-19 patients are strong predisposing factors. Cough, fever with shortness of breath are reliable symptoms for COVID-19 in our suspects. COVID-19 being an opportunistic infection contributes to a higher mortality in respiratory and cardiac patients.

Keyword: COVID-19; Contact history; Mortality; Symptoms stratification; Risk analysis; Survival

Citation: Khan $\mathrm{H}$, Khan $\mathrm{K}$, Khan $\mathrm{S}$ and Zar A. Risk factors and symptoms stratification and mortali

ty of COVID-19 in population of Nowshera (Pakistan). Anaesth. pain intensive c are. 2020;24(2): 196-104

DOI: https://doi.org/10.35975/apic.v24i2.1256 


\section{INTRODUCTION}

The recent emergence of a new respiratory disease called COVID-19 from a metropolitan city of the Hubei Province of China, called Wuhan, in December 2019, demonstrated its epidemic potential with a rapid spread of this virus across the globe in just two months period. This highlights the higher rate of transmissibility of this virus and further its higher morbidity and mortality, especially in aged population or people with co-morbidities and/or immune gap. ${ }^{1}$

COVID-19 is a highly contagious respiratory disease that is caused by novel corona virus. Its main clinical symptoms are fever, dry cough, fatigue, myalgia and dyspnea. ${ }^{2}$ Case fatality rate of $2.3 \%$ has been reported from china, that is lower than SARS (9.5\%), MERS (34.4\%) and H7N9 (39\%). ${ }^{3}$

In Pakistan, the literature so for covering the prevalence and incidence is still emerging and we found no published data. The reported data from government sources declares more than 6000 confirmed cases with 138 deaths. Punjab is the province with highest number of corona cases reaching 2000 at the time of writing this paper, and the toll is rising exponentially with each passing day. ${ }^{4}$

In Pakistan the virus entered on 26th February 2020, when Government of Pakistan officially declared that a student of University of Karachi with a travel history of Islamic Republic of Iran had been tested positive for COVID-19.

Literature describes that this virus is an opportunistic in nature, and attacks the elderly people and patients with other co-morbidities with serious outcome, that could lead to death due to severe respiratory distress and a cytokine storm in the body. ${ }^{6}$

Stress has been laid on identification and stratification of patients on the basis of the risk factors, e.g., history of close contact with COVID-19 positive patients, history of travel to an epidemic area like China, Iran, Italy etc. and identification of specific symptoms, as early identification can potentiate the surveillance process. $^{2,3,7}$

Studies from the epidemic areas have reported diverse presentation of COVID suspects/patients. A study from China reported a frequency of fever to be $82.1 \%$, dry cough $81 \%$ and dyspnoea $50 \%$. Lymphopenia was noted in $82.1 \%$ patients in their study. ${ }^{8}$ Similarly, another study by Zhao D et al. ${ }^{9}$ reported the most common symptoms to be fever and cough (78\% cases). A study from China reported a higher mortality of 54/191(28.27\%) from the city of Wuhan. It was attributed to older age and immunity gap in the deceased population. ${ }^{10}$

Present study was, therefore, designed to determine the risk factors stratification for COVID-19 in a selected portion of population, frequency of symptoms and to determine factors contributing to mortality due to COVID-19 in this population.

Research Hypotheses (Null, $\mathbf{H}_{\mathbf{0}}$ ): Hypotheses are the tentative answers for research questions. Based on literature search, following hypotheses were proposed to answers our research questions.

1. $\mathbf{H}_{\mathbf{0 1}}$ : There is no relation of viral infectivity with history of travel to an epidemic area of COVID-19 in population of district Nowshera (Objective 1)

2. $\mathbf{H}_{\mathbf{0 2}}$ : There is no relation of history of contact with COVID-19 patients and acquiring disease in population of district Nowshera (Objective 1)

3. $\mathbf{H}_{\mathbf{0 3}}$ : There is no difference in distribution of symptoms in COVID-19 and non-COVID respiratory disorders in population of district Nowshera (Objective 2)

\section{METHODOLOGY}

This comparative study was conducted from 15th February to 18th April, 2020 at Medical Teaching Institution, Qazi Hussain Ahmed Medical Complex (QHAMC), Nowshera. A 
total of 75 patients whose PCR reports were received were included in the study.

\section{Population \& Sampling:}

Assuming $4 \%$ prevalence of COVID-19 in general population from the study of Zhou X et al. ${ }^{11}$; a reference population of 100,000 patients was estimated to reside in the catchment area of our hospital, belonging to district Nowshera (Khyber Pakhtunkhwa -Pakistan). A sample size of 75 was calculated through open epi software, an online sample size calculator, with absolute precision of $5 \%$, confidence interval of $95 \%$, and a drop out of $10 \%$.

The sample was selected through consecutive, non-probability technique. All the patients from COVID clinics, or strong suspects with history of travel to an epidemic area or close contacts of COVID-19 positive patients, with PCR report received from the Khyber Medical University, Public Health Research Laboratory, irrespective of age and gender, were randomly selected.

All patients attended in emergency or outdoor patients department were excluded. Result awaiting suspects were also excluded. Similarly, patients attending the COVID-19 clinic without securing the optimum marks for selection to be enrolled of PCR testing were also excluded.

Ethical endorsement was obtained from the institutional ethical review board of Nowshera Medical College Hospital administration before the execution of the study.

Prior informed consent was obtained from all suspects and they were assured of confidentiality.

Thirty (40\%) of the cases were selected from COVID-19 clinic of Qazi Hussain Ahmed Medical Complex; however, the patients whose PCR was sent by the district health authorities were also included from the available district line list, and $45(60 \%)$ cases were received through District COVID-19 Focal Person, who is also one of the contributing authors.

All samples were sent under strict observance of protocols to the Public Health Research Laboratory of Khyber Medical University
Peshawar (a designated Lab for PCR of nCoV2019).

All of these patients, whose samples were collected, had been isolated mainly in the isolation unit of our hospital as well as designated quarantine areas; very few cases were allowed home isolation under strict observance of the health/district administration to contain the spread of the virus.

Results were received in 2- 3 days, all with positive PCR reports were isolated and kept under treatment, and their samples were repeated after 7 days of isolation/treatment. Those who were negative in repeated sample reporting were shifted to quarantine; one case that reported positive on second phase belonging to Karachi was kept under strict isolation.

\section{Operational definitions:}

Child: Article 1 of The United Nations Convention on the Rights of the Child defines a child as "for the purposes of the present Convention, a child means every human being below the age of $18 \mathrm{y}$ ". ${ }^{12}$

Adult: Young adult 19-40 y, middle-aged adult 41-60 y and older adult > $60 \mathrm{y} .{ }^{13}$

\section{Statistical analysis:}

Data were entered in SPSS $25^{\text {th }}$ version and descriptive and correlation statistics were applied. The frequency and proportion of numerical and categorical variables were presented in percentages. Chi-square test was applied to show a correlation of viral infectivity to gender, history of travel, history of contacts with COVID-19 patients and symptoms stratification for COVID-19.

Relative risk of COVID-19 was determined in gender groups, history of travel and history of contacts in COVID-19 positive and negative groups using risk analysis statistics.

We applied chi-square goodness-of-fit test on our population by positive and negative groups to test the null hypothesis $\mathbf{H}_{\mathbf{0 1}}, \mathbf{H}_{\mathbf{0 2}}$ and $\mathbf{H}_{\mathbf{0 3}}$. 


\section{RESULTS}

A total of 75 cases were enrolled for viral detection of 2019nCoV on PCR technique. Out of these, $20 \quad(26.67 \%)$ patients were females and 55 $(73.33 \%)$ were males. The age range was from $2-85 \mathrm{y}$, with the mean age being $36 \pm 18$ y (Table 1).

Out of 75 patients, $29(38.67 \%)$ were COVID-19 positive, and $46(61.33 \%)$ were negative. There was no significant relation of gender with viral infectivity $(\mathrm{p}=0.5)$; however, the probability of virus detection was higher in male gender $(\mathrm{OR}=1.5)$ and [Relative Risk $(\mathrm{RR})=1.2]$ as compared to female gender.

There was a significant relation of infectivity, and relatively high probability of getting infected in cases with history of travel to an epidemic area $(\mathrm{p}=0.01, \mathrm{OR}=3.85, \mathrm{RR}=1.5)$. Similarly there was a significant relation of infectivity, and relatively high probability of getting infected in cases with history of contacts with COVID-19 infected person $(\mathrm{p}=0.018$, OR $=3.5, \mathrm{RR}=2.3)($ Table 2).

We observed a higher mortality rate of $3 / 29$ $(10.34 \%)$. The probability of worse outcome in terms of death in COVID-19 positive patients was $(\mathrm{p}=0.5, \mathrm{OR}=2.1)$; it was not statistically significant. This probability reduces to $(\mathrm{OR}=$ 1.3) on suspects selection (Table 3 ).

The symptomatology and clinical features have a significant relation with result positivity, like contact and travel history with RI of $12 / 35$ (34\%) for positive cases. Similarly, cough, fever with shortness of breath had RI 8/12 (67\%) for positive cases followed by fever and cough with RI of 8/12 (67\%) cases etc. Many cases presented with symptoms of fever and sore throat turn out to be negative with RI of $1 / 13$
Gender wise distribution of patients. N (\%)

Female Male

Total

$14(19) \quad 32(43) \quad 46(61)$

$6(8) \quad 23(31) \quad 29(39)$

$20(26.67)$

$55(73.33)$

$75(100)$

PCR * AGECAT Cross tabulation

\section{AGECAT}

$$
<18 \text { y } 19-35 \text { y } 35-55 y \quad>55 y
$$

Total

\begin{tabular}{lccccc} 
Negative & 7 & 26 & 11 & 2 & 46 \\
\hline Positive & 3 & 8 & 10 & 8 & 29 \\
\hline Total & 10 & 34 & 21 & 10 & 75 \\
\hline
\end{tabular}

(8\%); hence sore throat is less reliable symptom in COVID-19. Similarly three cases of flue alone with RI 0/3(0\%) turned into a negative result, that disprove it to be a valid symptom in our population. The symptom selection has a significant relation with positivity of the result for COVID-19 $(p=0.01)$. (Table 4$)$.

We applied survival statistics using time to event analysis with Kaplan Meier Test method, taking age in years as time variable and disease outcome in event. We observed that survival rate in COVID-19 has an inverse relation with an increase in age. We observed the poor survival in age $>60 \mathrm{y}$ of age. But when we plotted the survival graphs of COVID positive vs COVID negative cases a similar pattern was observed that shows the mortality rate in the cases was not solely due to COVID-19, though being an opportunistic viral infection it would have contributed but the deceased had other comorbidities as well like coronary artery diseases and respiratory diseases etc. Figure 1 shows the relationship of age and PCR with the survival of the patients. 
Table 2: Viral infectivity and its relation with gender, history of travel to an epidemic area and history of contacts with an infected Covid-19 patient.

1.a .Gender-wise distribution and gender risk

\begin{tabular}{|c|c|c|c|c|c|c|}
\hline \multirow{2}{*}{ Gender } & \multicolumn{2}{|c|}{ PCR Report } & \multirow{2}{*}{ Total } & \multirow{2}{*}{$\begin{array}{c}\text { Asymptotic } \\
\text { Significance (2- } \\
\text { sided)-Chi Square } \\
\text { test }\end{array}$} & \multirow{2}{*}{$\begin{array}{l}\text { Relative } \\
\text { risk F/M }\end{array}$} & \multirow{2}{*}{$\begin{array}{c}\text { Odds } \\
\text { Ratio F/M }\end{array}$} \\
\hline & Negative & Positive & & & & \\
\hline Female & 14 & 6 & 20 & \multirow{3}{*}{$p=0.5$} & \multirow{3}{*}{1.2} & \multirow{3}{*}{1.5} \\
\hline Male & 32 & 23 & 55 & & & \\
\hline Total & 46 & 29 & 75 & & & \\
\hline
\end{tabular}

1.b. Relation of viral infectivity with travel history

\begin{tabular}{|c|c|c|c|c|c|c|}
\hline \multirow{2}{*}{ PCR } & \multicolumn{2}{|c|}{$\begin{array}{l}\text { Travel History to an } \\
\text { epidemic area }\end{array}$} & \multirow{2}{*}{ Total } & \multirow{2}{*}{$\begin{array}{c}\text { P-value } \\
\text { Asymptotic } \\
\text { Significance (2- } \\
\text { sided)-Chi Square } \\
\text { test }\end{array}$} & \multirow{2}{*}{$\begin{array}{l}\text { Relative } \\
\text { risk }\end{array}$} & \multirow{2}{*}{$\begin{array}{l}\text { Odds } \\
\text { Ratio }\end{array}$} \\
\hline & No & Yes & & & & \\
\hline Negative & 38 & 8 & 46 & \multirow{3}{*}{$p=0.01$} & \multirow{3}{*}{1.5} & \multirow{3}{*}{3.85} \\
\hline Positive & 16 & 13 & 29 & & & \\
\hline Total & 54 & 21 & 75 & & & \\
\hline
\end{tabular}

1.c. Relation of viral infectivity with contact history

\begin{tabular}{|c|c|c|c|c|c|c|}
\hline \multirow[t]{2}{*}{ PCR } & \multicolumn{2}{|c|}{$\begin{array}{c}\text { Contact History with } \\
\text { COVID-19 positive } \\
\text { case }\end{array}$} & \multirow[t]{2}{*}{ Total } & \multirow{2}{*}{$\begin{array}{c}\text { Asymptotic } \\
\text { Significance (2- } \\
\text { sided)-Chi Square } \\
\text { test }\end{array}$} & \multirow{2}{*}{$\begin{array}{l}\text { Relative } \\
\text { risk }\end{array}$} & \multirow{2}{*}{$\begin{array}{l}\text { Odds } \\
\text { Ratio }\end{array}$} \\
\hline & No & Yes & & & & \\
\hline Negative & 22 & 24 & 46 & \multirow{3}{*}{$p=0.018$} & \multirow{3}{*}{2.3} & \multirow{3}{*}{3.5} \\
\hline Positive & 6 & 23 & 29 & & & \\
\hline Total & 28 & 47 & 75 & & & \\
\hline
\end{tabular}

Table 3: Relation of viral infectivity with gender and outcome of the disease

\begin{tabular}{|c|c|c|c|c|c|c|}
\hline \multirow{2}{*}{$\begin{array}{c}\text { PCR } \\
\text { Result }\end{array}$} & \multicolumn{4}{|c|}{ Gender } & \multirow{2}{*}{$\begin{array}{l}\text { Asymptotic } \\
\text { Significance } \\
\text { (2-sided)-Chi } \\
\text { Square test }\end{array}$} & \multirow{2}{*}{$\begin{array}{c}\text { Odds Ratio for } \\
\text { PCR result vs } \\
\text { Outcome }\end{array}$} \\
\hline & Condition & Female & Male & Total & & \\
\hline Negative & Stable & 14 & 32 & 46 & 0 & 0 \\
\hline \multirow{3}{*}{ Positive } & Died & 1 & 2 & 3 & \multirow{3}{*}{0.5} & \multirow{3}{*}{2.1} \\
\hline & Stable & 5 & 21 & 26 & & \\
\hline & Total & 6 & 23 & 29 & & \\
\hline \multirow{3}{*}{ Total } & Died & 1 & 2 & 3 & \multirow{3}{*}{0.7} & \multirow{3}{*}{1.3} \\
\hline & Stable & 19 & 53 & 72 & & \\
\hline & Total & 20 & 55 & 75 & & \\
\hline
\end{tabular}


Risk factors and symptoms stratification and mortality of COVID-19 in population of Nowshera

Table 4: PCR * symptoms cross tabulation

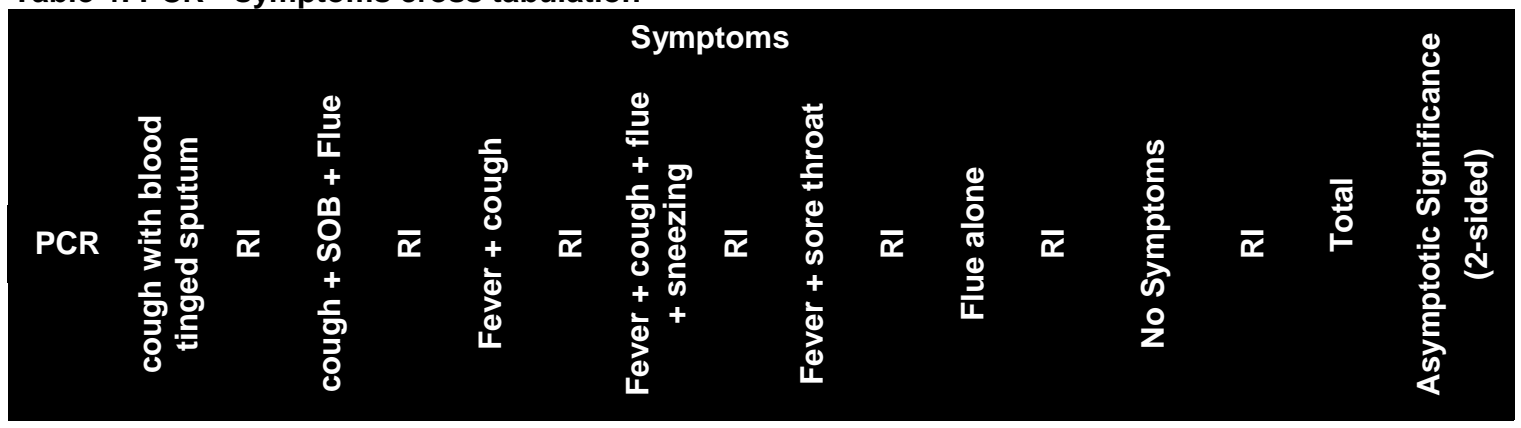

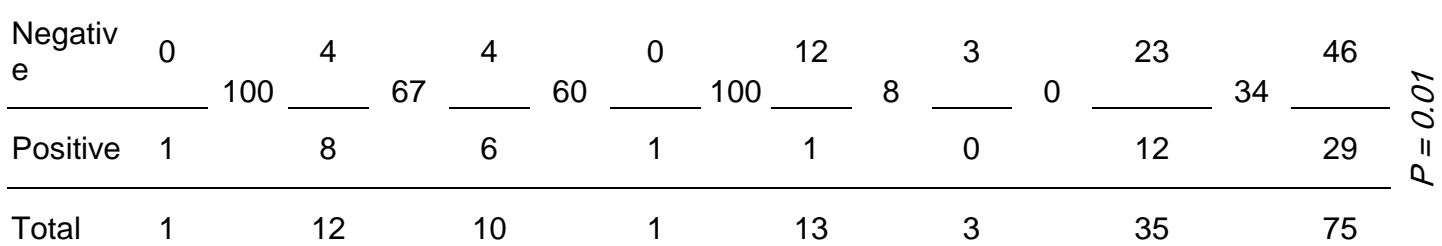

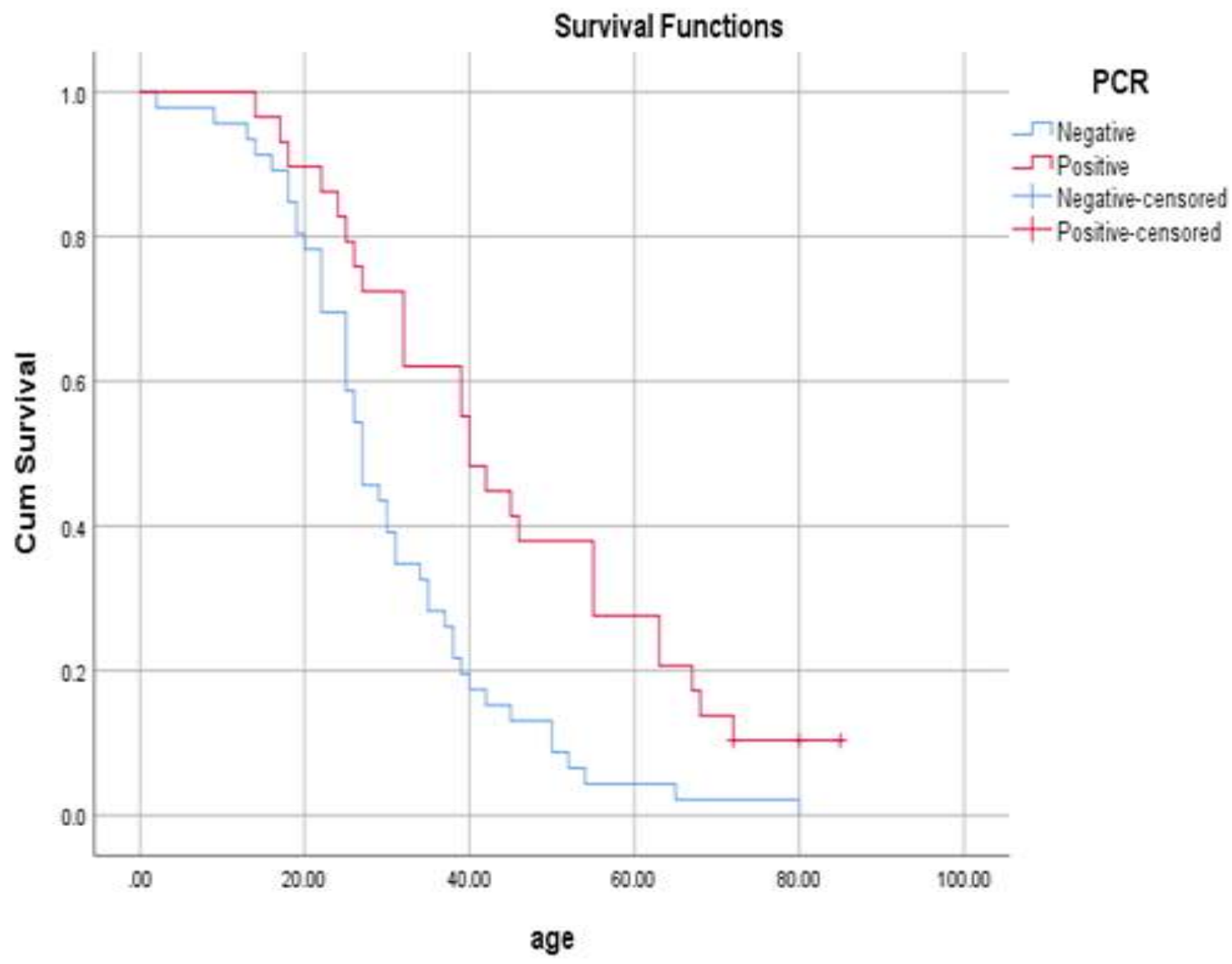

Figure 1: Relation of survival with age and PCR 


\section{DISCUSSION}

Research on population is a process to answer a question, to prove or disprove an assumption or hypothesis for a specified population on a specific issue. To the best of our knowledge this is the first ever study to give information on stratification of symptoms for COVID-19 in population of Nowshera, Pakistan. This is first intervention to discuss the risk factors and to show its statistical relation with the disease. This is first intervention to discuss mortality rate and factors contributing to mortality due to COVID-19 in Pakistan.

We here tried to identify the major risk factors of COVID-19 in our population. We observed that $29(38.67 \%)$ of the tested cases were COVID-19 positive, and $46(61.33 \%)$ were negative. There was no significant relation of gender with viral infectivity $(p=0.5)$; however, the probability of virus detection was higher in male gender [odd's ratio $(\mathrm{OR})=1.5)$ and $(\mathrm{RR}=$ 1.2 ) as compared to female gender.

Male gender predominance is also reported from Italy and China epidemic studies. New York time has reported that corona virus is striking and felling more Italian males as compared to females in extreme of age because of their weak immunity status. They further elaborated that Italian model of mortality is a trend mirror of what they observed in China with more causality in male gender and at extreme age. ${ }^{14,15 .}$

There was a significant relation of infectivity, and relatively high probability of getting infected in cases with history of travel to an epidemic area $(\mathrm{p}=0.01, \mathrm{OR}=3.85, \mathrm{RR}=1.5)$ that rejects the null hypothesis $\left(\mathbf{H}_{01}\right)$. Studies from China have reported a significant correlation of travel history to Wuhan and getting infection as compared to those without a travel history $(p=0.01){ }^{16,17}$ The findings of Zhou X et al. $(17 \%)^{17}$ and Tian $\mathrm{S}$ et al. $(5 \%),{ }^{18}$ match to our study who reported a strong correlation of acquiring infection in those reporting with history of travel to high epidemic areas of China.
Similarly, there was a significant relation of infectivity, and relatively high probability of getting infected in cases with history of contacts with COVID-19 infected person $(\mathrm{p}=0.018$, OR $=3.5, \mathrm{RR}=2.3)$ which rejects the null hypothesis $\left(\mathbf{H}_{02}\right)$ that there is no relation of viral infectivity with history of travel to an epidemic area. The findings of Luo L, et al. ${ }^{19}$ and Qiu $\mathrm{H}$ et $\mathrm{al}^{20}$ match our results where they reported a higher rate of prevalence of COVID-19 in their target population with a strong history of contacts with positive COVID patients.

Regarding the clinical features/symptoms of the disease, it was observed that cough, fever and shortness of breath (SOB) has a high RI of 8/12 (67\%) for case positivity, followed by fever and cough without SOB, with RI of 8/12 (67\%) cases etc.

It was noted that sore throat complainants turned out to be negative with RI of $1 / 13(8 \%)$; that proves sore throat as a less reliable symptom for COVID-19.

Similarly, flu alone with RI 0/3 (0\%) negative result proves it as an invalid symptom in our population. The symptom selection has a significant relation with positivity of the result for COVID-19 $(p=0.01)$ that rejects the null hypothesis $\left(\boldsymbol{H}_{03}\right)$. Zhao D et al. ${ }^{9}$ also reported fever and cough in (78\%) of confirmed COVID19 cases that strongly coincides with our findings.

We observed that survival rate in COVID-19 has an inverse relation with an increase in age. When we plotted the survival graphs of COVID positive vs COVID negative cases, a similar pattern was observed that shows the mortality rate in the cases was not solely due to COVID19 , though being an opportunistic viral infection it would have contributed.

But there were co-morbidities in the deceased; we observed in case of one female patient $85 \mathrm{y}$ old was admitted in medical unit with other comorbidities (CAD/COPD) and age factor along with COVID infectivity. Another case had coronary artery disease (CAD) and age factor. One case that was cross reported from Peshawar (Khyber Teaching Hospital) the report showed he was critically ill with CAD, and was $>75 \mathrm{y}$ 
old along with COVID-19 infection. That might be the reason of the Kaplan Meier test that reported insignificant difference in mortality caused by COVID-19 and vice versa.

The CDC reports 2019 shows that $53 \%$ of the COVID-19 infected patients that need ICU admission, and those $80 \%$ of the deaths were recorded in elderly people age $>65 \mathrm{y}$, while no ICU admission or deaths were recorded in age less than $19 \mathrm{y}$ of age. ${ }^{21}$

In 4/29 (13.79\%) of our patients in QHAMC the refractory COVID was recorded in repeated PCR after 10 days. All the four cases were males. It has been reported from China that cases with refractory COVID-19 were mostly males and with manifestation of fever, shortness of breath, as were our observation $(\mathrm{p}<0.05)^{22}$.

Based upon the results of our study, it is suggested that special care should be given to suspects with higher risks like in age $>60 \mathrm{y}$, and patients with immunity gaps and other comorbidities.

It is suggested that further studies should be carried out covering maximum duration of study, maximum number of positive patients, and if possible to cover a higher number of deaths reported so far, to correlate different risk factors with morbidity and mortality of COVID19.

\section{CONCLUSION}

Hence it is concluded that male gender, with history of travel to an epidemic area and contact with COVID-19 patients, are strong predisposing factors. Cough and fever with shortness of breath are reliable symptoms for COVID-19 in our study. Fever and oxygen dependency are strongly correlated to refractory COVID-19. COVID-19 being an opportunistic infection contributes to a higher mortality in respiratory and cardiac disease in elderly patients.

\section{Acknowledgements:}

The authors are highly indebted to the following for their support for completion of this study;

1. Dr. Mohammad Arif. zHospital Director, Qazi Hussain Ahmed Medical Complex, Nowshera

2. Professor Fazli Bari, Professor of Microbiology, Chairman, Infection control committee, Nowshera Medical College, Nowshera.

3. Dr. Mian Mohammad Naveed, Focal person COVID-19, Mian Rashid Husssain Shaheed Memorial Hospital, Nowshera.

4. Dr. Mohammad Zahid Khan, Focal person COVID-19, Qazi Hussain Ahmed Medical Complex, Nowshera.

Conflict of interest:

None declared by the authors.

Authors' contribution:

HK - Concept, conduction of the study work, literature search, and manuscript editing

$\mathrm{KH}$ - Concept, conduction of the study work, literature search,

ST, AZ - Concept, manuscript editing 


\section{REFERENCES}

1. Weston S, Frieman MB. COVID-19: knowns, unknowns, and questions. mSphere. 2020;5(2):e00203-20. [PubMed] DOI: $10.1128 / \mathrm{mSphere.00203-20}$

2. Chen N, Zhou M, Dong X, Qu J, Gong $F$, Han $Y$, et al. Epidemiological and clinical characteristics of 99 cases of 2019 novel coronavirus pneumonia in Wuhan, China: a descriptive study. Lancet. 2020;395(10223):507 -13. [PubMed] DOI: $10.1016 / \mathrm{S} 0140$ 6736(20)30211-7

3. Munster VJ, Koopmans M, van Doremalen $\mathrm{N}$, van Riel $\mathrm{D}$, de Wit E. A Novel coronavirus emerging in China - key questions for impact assessment. N Engl J Med. 2020;382(8):692-4. [PubMed] DOI: $10.1056 /$ NEJMp2000929

4. Coronavirus in Pakistan - Confirmed Cases. Available from: www.covid.gov.pk/ [Accessed 6 April 2020].

5. Arab News PK. Pakistan prepares to fight back as two coronavirus cases emerge in country. Available from: https://arab.news/rawae. [Accessed 4 March 2020].

6. Guo YR, Cao QD, Hong ZS, Tan $Y Y$, Chen SD, Jin HJ, et al. The origin, transmission and clinical therapies on coronavirus disease 2019 (COVID-19) outbreak - an update on the status. Mil Med Res. 2020 Mar 13;7(1):11. [PubMed] DOI: 10.1186/s40779-020-00240-0

7. Jin $\mathrm{YH}$, Cai L, Cheng ZS, Cheng $\mathrm{H}$, Deng T, Fan YP, et al. A rapid advice guideline for the diagnosis and treatment of 2019 novel coronavirus (2019-nCoV) infected pneumonia (standard version). Mil Med Res. 2020 Feb 6;7(1):4. [PubMed] DOI: 10.1186/s40779020-0233-6

8. Zhang L, Zhu F, Xie L, Wang $\underline{\mathrm{C}}$, Wang $\mathrm{J}$, Chen R, Jia P, et al. Clinical characteristics of COVID- 19-infected cancer patients: A retrospective case study in three hospitals within Wuhan, China. Ann Oncol. 2020 Mar 26. pii: S09237534(20)36383-3. [PubMed] DOI: 10.1016/.annonc.2020.03.296

9. Zhao $D$, Yao $F$, Wang L, Zheng L, Gao Y,$\underline{Y e ~ J}$, et al. A comparative study on the clinical features of COVID-19 pneumonia to other pneumonias. Clin Infect Dis. 2020 Mar 12. pii: ciaa247. [PubMed] DOI: 10.1093/cid/ciaa247

10. Zhou F, Yu T, Du R, Fan G, Liu Y, et al. Clinical course and risk factors for mortality of adult in patients with COVID-19 in Wuhan, China: a retrospective cohort study. Lancet. 2020;395(10229):1054-62.

[PubMed] DOI: $10.1016 / \mathrm{S} 0140-$ 6736(20)30566-3

11. Zhou X, Li Y, Li T, Zhang $W$. Follow-up of the asymptomatic patients with SARS-CoV-2 infection. Clin Microbiol Infect. 2020 Mar 28. pii: S1198-743X(20)30169$5 . \quad$ [PubMed] DOl: 10.1016/j.cmi.2020.03.024

12. UNICEF UK. The United Nations Convention on the Rights of the Child. Available from: https://www.unicef.org.uk/what-wedo/un-convention-child-rights/ [Accessed Jan 13 2019].

13. Petry NM. A comparison of young, middle-aged, and older adult treatment-seeking pathological gamblers. Gerontologist. 2002 Feb;42(1):92-9. [PubMed] DOl: 10.1093/geront/42.1.92

14. Cascella M, Rajnik M, Cuomo A, Dulebohn S, Napoli R. Features, evaluation and treatment coronavirus (COVID-19). Treasure Island (FL): StatPearls Publishing; 2020. Available from: https://www.ncbi.nlm.nih.gov/books/ NBK554776/

15. National Health Commission of People's Republic of China. Notice on printing and distributing the work plan for prevention and control of pneumonia caused by novel coronavirus infection in the near future. Available from: http://www.nhc.gov.cn/tigs/s7848/20 2001/808bbf75e5ce415aa19f74c78 ddc653f.shtml [Accessed 31 Jan 2020].

16. Lau H, Khosrawipour V, Kocbach $P$, Mikolajczyk A, Lchii $H$, Schubert J, et al. Internationally lost COVID-19 cases. J Microbiol Immunol Infect. 2020. DOI: 10.1016/j.jmii.2020.03.013

17. Zhou X, Li Y, Li T, Zhang $W$. Follow-up of the asymptomatic patients with SARS-CoV-2 infection. Clin Microbiol Infect. 2020 Mar 28. pii: S1198-743X(20)30169$5 . \quad$ [PubMed] DOI: 10.1016/i.cmi.2020.03.024

18. Tian S, Hu N, Lou J, Chen K, Kang $X$, Xiang Z, et al. Characteristics of COVID-19 infection in Beijing. J Infect 2020;80(4):401-6. [PubMed] DOI: 10.1016/j.jinf.2020.02.018

19. Luo L, Liu $\mathrm{D}$, Liao $\mathrm{XL}$, $\mathrm{Wu}$ $X B$, Jing $Q L$, Zheng JZ, et al. Modes of contact and risk of transmission in COVID-19 among close contacts. medRxiv. 2020;20042606. DOI: 10. 1101/2020.03.24.20042606

20. Qiu H, Wu J, Hong L, Luo Y, Song Q, Chen D. Clinical and epidemiological features of 36 children with coronavirus disease 2019 (COVID). Lancet. 2020. DOI: 10.1016/S1473-3099(20)30198-5

21. CDC COVID-19 Response Team. Severe outcomes among patients with Coronavirus Disease 2019 (COVID-19) - United States, February 12-March 16, 2020. MMWR Morb Mortal Wkly Rep. 2020;69(12):343-6. [PubMed] DOI: $\underline{10.15585 / \mathrm{mmwr} . \mathrm{mm} 6912 \mathrm{e} 2}$ 